\title{
Absolute Intensities of the Vacuum Ultraviolet Spectra in a Metal-Etch Plasma Processing Discharge
}

J. R. Woodworth, M. G. Blain, R. L. Jarecki, T. W. Hamilton, and B. P. Aragon: Sandia National Laboratories, Albuquerque, New Mexico 87185-1423

\begin{abstract}
DEC 141998

OSTI

In this paper we report absolute intensities of vacuum ultraviolet and near ultraviolet emission lines (4.8 eV to $18 \mathrm{eV}$ ) for aluminum etching discharges in an inductively coupled plasma reactor. We report line intensities as a function of wafer type, pressure, gas mixture and rf excitation level. In a standard aluminum etching mixture containing $\mathrm{Cl}_{2}$ and $\mathrm{BCl}_{3}$ almost all the light emitted at energies exceeding $8.8 \mathrm{eV}$ was due to neutral atomic chlorine. Optical trapping of the VUV radiation in the discharge complicates calculations of VUV fluxes to the wafer. However, we see total photon fluxes to the wafer at energies above $8.8 \mathrm{eV}$ on the order of $4 \times 10^{14}$ photons $/ \mathrm{cm}^{2} \mathrm{sec}$ with a nonreactive wafer and $0.7 \times 10^{14}$ photons $/ \mathrm{cm}^{2} \mathrm{sec}$ with a reactive wafer. The majority of the radiation observed was between 8.9 and $9.3 \mathrm{eV}$. At these energies, the photons have enough energy to create electron-hole pairs in $\mathrm{SiO}_{2}$, but may penetrate up to a micron into the $\mathrm{SiO}_{2}$ before being absorbed. Relevance of these measurements to vacuum-UV photon-induced damage of $\mathrm{SiO}_{2}$ during etching is discussed.
\end{abstract}

RECEIVED 


\section{DISCLAIMER}

This report was prepared as an account of work sponsored by an agency of the United States Government. Neither the United States Government nor any agency thereof, nor any of their employees, make any warranty, express or implied, or assumes any legal liability or responsibility for the accuracy, completeness, or usefulness of any information, apparatus, product, or process disclosed, or represents that its use would not infringe privately owned rights. Reference herein to any specific commercial product, process, or service by trade name, trademark, manufacturer, or otherwise does not necessarily constitute or imply its endorsement, recommendation, or favoring by the United States Government or any agency thereof. The views and opinions of authors expressed herein do not necessarily state or reflect those of the United States Government or any agency thereof. 


\section{DISCLAIMER}

\section{Portions of this document may be illegible in electronic image products. Images are produced from the best available original document.}




\section{Introduction}

For many years, there has been concern that plasma etching processes used to fabricate microelectronic circuits may also cause damage to the circuits being fabricated. ${ }^{1,2,3,4,5}$ This concern has become more acute as the feature sizes in microelectronic circuits continue to shrink. Microcircuits can be damaged by energetic ions, ${ }^{6,7,8}$ by electrons, ${ }^{9}$ by metastable atoms ${ }^{10}$, or by energetic photons from the vacuum ultraviolet $t^{5,11,12,13,14,15,16}$ to the gamma ray ${ }^{17,18}$ range. Plasma nonuniformities can cause charging damage to microelectronic circuits ${ }^{19,20,21}$. This fact, in addition to the desire for process uniformity, has led plasma etching tool manufacturers to design inductively-coupled reactors, in which the ion energies and fluxes can be varied independently and in which the plasma is very uniform across the wafer surface ${ }^{22}$.

Vacuum ultraviolet photons with energies greater than the 8.8-eV band gap energy in $\mathrm{SiO}_{2}$ will be absorbed in the $\mathrm{SiO}_{2}$ producing electron-hole pairs and $\mathrm{E}^{\prime}$ defect centers. The holes may become trapped near $\mathrm{Si} / \mathrm{SiO}_{2}$ interfaces causing degradation in device characteristics such as dielectric breakdown ${ }^{20}$, declines in the lifetime for minority carriers, and a flatband voltage shift in transistors ${ }^{15,17} . \mathrm{E}^{\prime}$ centers in $\mathrm{SiO}_{2}$ can absorb light at energies as low as $5.8 \mathrm{eV}$, making the device much more susceptible to damage ${ }^{23}$. While several authors have reported vacuum ultraviolet spectra of plasma sources related to microelectronic processing ${ }^{15,24,25}$, we are not aware of any references that report 
absolute intensities of the vacuum ultraviolet spectra in high-density, inductivelycoupled, microelectronic processing discharges. In this paper we report absolute intensities of vacuum ultraviolet and near ultraviolet emission lines $(4.8 \mathrm{eV}$ to $18 \mathrm{eV})$ for aluminum etching discharges in a commercial, inductively coupled plasma etching reactor $^{22}$. We report data as a function of wafer type, pressure, gas mixture and rf excitation level.

\section{Apparatus}

An Applied Materials Centura, decoupled plasma source (DPS ) metal etch chamber was used for the work presented here. This chamber is designed to minimize plasma processing induced damage on the wafer ${ }^{22}$. Similar to other high density plasma systems, DPS has two rf sources. The inductively coupled plasma is generated and sustained through the rf "source power " $\left(\mathrm{W}_{\mathrm{s}}\right)$ at a frequency of $2 \mathrm{MHz}$ applied to the coil on top of the chamber. The ion bombardment energy is controlled through the rf "bias power" $\left(\mathrm{W}_{\mathrm{b}}\right)$ at $13.56 \mathrm{MHz}$, which is applied through the electrode to the wafer through capacitive coupling. This chamber has been designed to minimize the plasma nonuniformity ${ }^{26}$ across the wafer and to minimize the amount of bias power required. Typical ratios of source power to bias power are above 7:1.

The spectrometer used in these experiments was a 0.5 -meter focal-length spectrometer of the Seya-Namioka (SEYA) design. A schematic of this spectrometer attached to the DPS tool is shown in Fig. 1. The SEYA had a single curved diffraction grating as its sole optical element. This grating, which was gold coated and had 1200 lines $/ \mathrm{mm}$, both diffracted the light and focused it to the exit slit. No window materials exist that will 
pass light at energies above $11 \mathrm{eV}$. We therefore coupled the spectrometer directly to the DPS tool, with only the 25-micron-wide, 3-mm-long entrance slit separating the DPS chamber discharge ( 10 to $30 \mathrm{mTorr}$ ) from the spectrometer, which was kept at a moderate vacuum $\left(\sim 10^{-5}\right.$ Torr $)$. Some of the gases from the DPS discharge unavoidably entered the spectrometer, striking the grating and detectors and slowly lowering their efficiencies during the course of the experiments. The SEYA viewed a relatively narrow cone of light ( $F / 20$ ) that traversed the diameter of the DPS plasma, just above the focus ring and approximately $3.7 \mathrm{~cm}$ above the wafer. The spectrometer exit slit was intentionally set somewhat wider than the entrance slit in these experiments. This lowered the resolution of the spectra slightly, but produced "flat-topped" spectral lines, considerably simplifying the calibrations for the absolute fluxes.

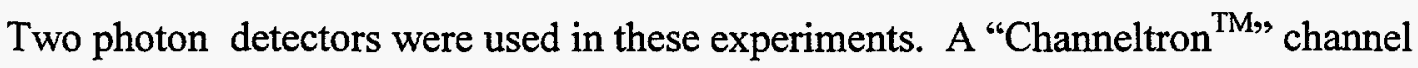
electron multiplier ${ }^{27}$ was placed behind the exit slit to measure photons with energies from $8 \mathrm{eV}$ to $17 \mathrm{eV}$. A photomultiplier tube with a magnesium fluoride window and a cesium telluride photocathode was used to detect photons having energies from $4 \mathrm{eV}$ to $11 \mathrm{eV}$.

To calibrate the sensitivity of the SEYA plus detectors, we coupled the entrance slit of the SEYA to the exit slit of a 1-meter focal length spectrometer as shown in Fig. 2. This 1-meter spectrometer, with various light sources, was used to provide a monochromatic input beam to the SEYA. At each calibration wavelength, the intensity of the light entering the SEYA was measured with a photodiode calibrated by the National Institute of Standards \& Technology (NIST) ${ }^{28}$. The NIST photodiode was mounted so that it could be moved into or out of the beam at a location between the SEYA's entrance slit 
and grating. Comparing the intensity measured with the NIST photodiode to the signal produced by the channeltron or photomultiplier at the SEYA exit slit allowed us to determine the sensitivity of the SEYA + detector system.

Several light sources were used to provide UV light for the calibrations. A deuterium hollow cathode lamp with a magnesium fluoride window was used to provide a number of calibration lines between 120 and $210 \mathrm{~nm}$. A windowless, rf-excited discharge lamp built at Sandia ( shown in figure 2 ) was used to provide intense resonance lines of the noble gases, from helium at $58.4 \mathrm{~nm}$ to Xe at $147 \mathrm{~nm}$. There was one stage of differential pumping between this lamp, which was typically operated at $80 \mathrm{mTorr}$ and the 1-meter spectrometer which operated at $\sim 10^{-5}$ Torr. A mercury pen lamp was used to provide spectra at $254 \mathrm{~nm}$. Figure 3 shows a calibration curve of the sensitivity of the SEYA plus channeltron versus wavelength. The strong variation in sensitivity with wavelength shows the importance of calibrating the system.

The sensitivity of the SEYA plus detectors was determined before and after measurements on the plasma processing chamber. The change in grating + detector efficiency caused by etch process gases in the SEYA caused the major uncertainty in the calibrations. For the SEYA + channeltron, the total uncertainties on the absolute flux numbers are $\pm 63 \%$, because both the grating and the channeltron were affected by the gases from the discharge. For the SEYA + PMT data the uncertainties are + $43 \%,-33 \%$. Relative uncertainties within any data set taken on a single day should be much smaller than the uncertainties listed above as individual measurements of spectrometer + detector efficiency were generally repeatable to better than $10 \%$. 
Using the signals from the detectors and the known sensitivity of the SEYA + detector combination, we derived the wavelength-dependent flux of photons in the cone of light passing through the SEYA's entrance slit and striking the grating. For our $\sim \mathrm{f} / 20$ spectrometer, this cone of light subtended a solid angle of $2.6 \times 10^{-3}$ steradians. We then calculated the number of photons an elemental area of the discharge radiated into $4 \pi$ steradians using the relationship ${ }^{29}$ :

$I_{g}=(N A L / 4 \pi) *\left(A_{s} A_{g} / F^{2}\right)$

Where:

$I_{g}=$ number of photons $/ \mathrm{sec}$ striking grating

$\mathrm{NA}=$ number of photons $/ \mathrm{cm}^{3} \mathrm{sec}$ radiated into $4 \pi$ steradians by an elemental volume in the discharge

$\mathrm{L}=$ length of discharge column

$A_{s}=$ area of spectrometer entrance slit

$A_{g}=$ Projected area of grating as viewed from entrance slit.

$\mathrm{F}=$ Distance from entrance slit to diffraction grating.

To calculate the photon flux to the center of the wafer $\left(I_{w}\right)$, we then approximated the discharge as a uniformly emitting hemispherical volume with a radius of $17.3 \mathrm{~cm}$. 
While this neglects the effect of the focus ring on the discharge, this should be a small effect on the photon flux striking the center of the wafer. We also assumed that the plasma was transparent to the VUV radiation - i.e. that these was no radiation trapping in the plasma. Integrating over the hemispherical volume of the plasma gave us the relationship:

$$
\begin{array}{ll}
I_{w}= & N A \iiint\left\{\cos \theta /\left(4 \pi r^{2}\right)\right\} r^{2} \sin \theta d r d \theta d \varphi \\
I_{w}= & (N A / 4 \pi) \iiint \sin \theta \cos \theta d r d \theta d \varphi=(17.3 N A) / 4
\end{array}
$$

Where the limits of integration are: $r=0$ to $17.3, \theta=0$ to $\pi / 2, \varphi=0$ to $2 \pi$ and $I_{w}$ is the photon flux at the center of the wafer in photons $/ \mathrm{cm}^{2} \mathrm{sec}$.

\section{Results:}

The VUV fluxes in the DPS chamber were examined with four different wafer materials on the chuck: a solid aluminum-oxide ceramic wafer, a solid aluminum metal wafer, a photoresist-covered silicon wafer, and a bare silicon wafer. Figure 4 shows a plot of the VUV spectra from 90 to $140 \mathrm{~nm}(13.7 \mathrm{eV}$ to $8.8 \mathrm{eV})$ with the ceramic wafer in place for our baseline case of a $10 \mathrm{mTorr}$ discharge with a 100 sccm flow of $\mathrm{Cl}_{2}$ and a $40 \mathrm{sccm}$ flow of $\mathrm{BCl}_{3}$. The discharge was excited by 1100 $\mathrm{W}$ of source power and $200 \mathrm{~W}$ of bias power. In Fig. 4 the intensities are listed in 
terms of the photon flux at the center of the wafer using the assumption that the plasma is transparent to the VUV radiation. Note that the intensities have been divided by $10^{14}$. For the data shown in Fig. 4, with the ceramic wafer in the chuck, the VUV photon flux passing through the SEYA entrance slit in the $2.6 \times 10^{-3}$ steradian cone that struck the diffraction grating was $1.4 \times 10^{13}$ photons $/ \mathrm{cm}^{3} \mathrm{sec}$. Using the calculations in the previous section, this corresponds to a flux of VUV photons above $8.8 \mathrm{eV}$ to the center of the wafer of $4.8 \times 10^{14}$ photons $/ \mathrm{cm}^{3} \mathrm{sec}$. With the silicon, aluminum metal, or photoresist covered wafers in the chuck, the fluxes were essentially identical, but a factor of $\sim 6$ lower than the fluxes with the ceramic wafer in the chuck. For the silicon wafer, the VUV flux passing through the SEYA entrance slit in the cone angle striking the diffraction grating was $0.2 \times 10^{13}$ photons $/ \mathrm{cm}^{3} \mathrm{sec}$. This corresponds to a flux of VUV photons above $8.8 \mathrm{eV}$ to the center of the wafer of $7 \times 10^{13}$ photons $/ \mathrm{cm}^{3} \mathrm{sec}$. This decrease in flux when a reactive wafer is in the tool was probably caused by two effects: 1) depletion of chlorine through reactions with the wafer material and 2) quenching of excited chlorine atoms by collisions with etch-product molecules. This lower flux $\left(7 \times 10^{13}\right.$ photons $\left./ \mathrm{cm}^{2} \mathrm{sec}\right)$ is most representative of actual wafer processing conditions.

All of the spectral lines between 115 and $140 \mathrm{~nm}$ are emissions from excited state to ground state transitions in neutral chlorine atoms, with most of the energy being between 132 and $140 \mathrm{~nm}$ - just above the $8.8 \mathrm{eV}$ band gap energy of $\mathrm{SiO}_{2}$. The fact that these transitions terminate on the ground state suggests that radiation trapping 
may be affecting the VUV fluxes we measure. This point will be discussed in detail in the next section.

We saw no emission lines brighter than $1 \times 10^{11}$ photons $/ \mathrm{cm}^{2} \mathrm{sec}$ at wavelengths between 68 and $95 \mathrm{~nm}$ ( 13 to $18 \mathrm{eV}$ ). The wavelengths of the neutral chlorine emission lines between 115 and $140 \mathrm{~nm}$ and their intensities are listed in Table I for the baseline case shown in Fig. 4 with the ceramic wafer in place. The relative intensities of the various neutral chlorine lines did not appear to vary as we varied wafer type, pressure or rf power - only the total intensity varied. We were not able to positively identify the weak spectral features between 95 and $115 \mathrm{~nm}$. These spectral lines are shown in more detail in Fig. 5.

Figure 6 shows a plot of the spectra between 110 and $250 \mathrm{~nm}$ that we observed with the photomultiplier tube, when looking at the same discharge as shown in Fig. 5. In addition to the neutral chlorine lines (in first and second order of the spectrometer ) a number of atomic boron lines are visible. The intensities of the chlorine lines in Fig. 6 are about a factor of two lower than the intensities measured with the channeltron. This difference is probably due to the change in grating and detector efficiencies during the experiments.

Figure 7 shows a plot of the total VUV power striking the center of the wafer for our $10 \mathrm{mTorr}, 100 \mathrm{sccm} \mathrm{Cl} 240 \mathrm{sccm} \mathrm{BCl}$ mixtures over a ceramic wafer as a function of total rf power. The source/bias power is listed next to each data point in Fig. 7. 
Note that the VUV energy striking the wafer appears to depend linearly on the sum of the source + bias power applied to the discharge. There are two data points with essentially identical values at $1100 \mathrm{~W}$ source $/ 0 \mathrm{~W}$ bias. One of these points was for the $\mathrm{Cl}_{2} / \mathrm{BCl}_{3}$ mixture, the other is for a pure Ar mixture. While the VUV spectra for these two points was quite different ( in the pure Ar case, all the VUV light was emitted in the two Ar resonance lines at 104.8 and $106.6 \mathrm{~nm}$ ) it is interesting to note that the overall VUV intensities were almost identical.

Tables II - IV list photon fluxes above $8.8 \mathrm{eV}$ as measured with the SEYA + Channeltron for a variety of conditions. Table II shows photon fluxes for our standard $10 \mathrm{mTorr}, 1100 \mathrm{~W} / 200 \mathrm{~W}$ discharge as a function of wafer type. Note that any type of reacting wafer material lowers the VUV flux to the wafer by more than a factor of 6 .

Table III shows that VUV fluxes increase slightly as discharge pressure is increased from 5 to $20 \mathrm{mT}$ Torr. Table IV examines a different set of gas mixtures: $7 \mathrm{mT}$ total pressure, $60 \mathrm{sccm} \mathrm{Cl}_{2} 30 \mathrm{sccm} \mathrm{BCl} l_{3}$ with and without $50 \mathrm{sccm}$ of $\mathrm{Ar}$. RF source and bias powers were $900 \mathrm{~W}$ and $185 \mathrm{~W}$ respectively. The slight increase in VUV intensity seen when the Ar is added is entirely due to the addition of the two $\mathrm{Ar}$ resonance lines.

Table V shows VUV fluxes as measured with the photomultiplier tube for our standard discharge: $10 \mathrm{mT}, 100 \mathrm{sccm} \mathrm{Cl}_{2} / 40 \mathrm{sccm} \mathrm{BCl}_{3}$ and $1100 \mathrm{~W}$ source/200 W 
bias power. As noted earlier, the VUV fluxes measured with the photomultiplier tube are about a factor of two lower than the fluxes measured with the channeltron.

\section{Discussion}

Spectral Lines:

Most of the spectral lines we saw at energies above $8.8 \mathrm{eV}$ in these experiments were due to neutral chlorine atoms and were between 8.9 and $10.6 \mathrm{eV}$. In addition we saw a series of weak emission features between 11 and $12.7 \mathrm{eV}$. We saw no emissions between 12.7 and $18 \mathrm{eV}$ and we could easily have detected an emission feature with an intensity of $2 \times 10^{11}$ photons $/ \mathrm{cm}^{2}$. We did not see any emissions from chlorine ions and we could easily have detected a number of chlorine ion emission lines near $107 \mathrm{~nm}$ if they had been present. This absence of short wavelength emission lines at energies above $13.7 \mathrm{eV}$ or chlorine ion lines in our discharges is not too surprising. The first excited state of the chlorine ion is $11.5 \mathrm{eV}$ above the ionic ground state and the ionization potential of neutral chlorine is $12.96 \mathrm{eV}$. Previous Langmuir probe measurements ${ }^{30}$ in plasmas similar to this one have indicated that the electron temperatures vary from $2 \mathrm{eV}$ to $5 \mathrm{eV}$. Thus, we would expect relatively few of the chlorine atoms to be excited to higher lying excited states of the atom and very few to be excited $\sim 24.5 \mathrm{eV}$ above the atomic ground state to the first excited state of the chlorine ion. Further, we would expect any highly excited states capable of producing short wavelength photons to be rapidly quenched by collisions with the large number of neutral chlorine atoms in our discharges. 
Optical Trapping:

It is important to note that almost all of the emission lines we saw above $8.8 \mathrm{eV}$ are resonance transitions in atomic chlorine. That is, they are allowed transitions from excited states to the ground state of the atom. As a consequence, most of these lines are strongly radiation trapped in the discharge. ${ }^{31,32,33,34}$ Our discharges typically operated at a $10 \mathrm{mTorr}$ total pressure. Previous work has indicated that most of the $\mathrm{Cl}_{2}$ molecules in our discharges are dissociated and that all of the fine structure states of the ground state are thermally populated ${ }^{35}$. This implies that our ground state $\mathrm{Cl}$ atom densities were on the order of $10^{14} \mathrm{~cm}^{-3}$. The chlorine lines emitted between 119 and $135 \mathrm{~nm}$ have radiative lifetimes on the order of a few nanoseconds ${ }^{36}$ and hence have line center absorption cross-sections ${ }^{37}$ on the order of $10^{-12} \mathrm{~cm}^{2}$. Thus, light from these transitions which is emitted on line center will be reabsorbed by the time it travels 100 microns through the discharge. The emission lines between 135 and $140 \mathrm{~nm}$ are weaker transitions; line-center light from these transitions may travel 1 to $10 \mathrm{~cm}$ through the discharge before being absorbed. As a consequence of this radiation trapping, much of the light which strikes the wafer or the entrance slit of our spectrometer will originate from atoms close to the wafer or slit instead of uniformly from atoms throughout the discharge. Also, the spectral lines of the light emerging from the discharge will be broadened and will have a strong absorption dip in their center. The resolution of our spectrometer, however, is much too low to resolve this complex lineshape. 
Another way of analyzing discharges with optical trapping examines the effective lifetime of photons in a discharge ${ }^{34}$ - i.e. the time it takes photons to diffuse out of the discharge through successive absorptions and re-emissions. As long as the decay rate due to this effective lifetime is much larger than any non-radiative decay rates in the medium, the total flux of photon energy emerging from the discharge will not be affected by the radiation trapping. If the non radiative decay rates ( due to collisions with walls, or collisions with etch product molecules ) are comparable to the effective radiative decay rate, the optical trapping will lower the flux of photons emerging from the discharge. Analysis of the optical trapping using Holstein ${ }^{31}$ and Riley's ${ }^{34}$ techniques suggest that the photons in our discharges will have effective radiationtrapped radiative lifetimes on the order of 1 to 10 microseconds, depending on the transition. This is much longer than the $2-10 \mathrm{~ns}$ radiative lifetimes of most of the transitions in the absence of optical trapping. It is still much shorter, however, than the $100-200$ microsec. a chlorine atom would take to traverse the discharge and strike the chamber wall, so collisions with the walls should not seriously affect the flux of VUV photons. Unfortunately, we cannot quantify the non-radiative decay rates due to collisions with etch products. Neither the densities of the etch products nor their reaction cross-sections for quenching excited $\mathrm{Cl}$ atoms are known. Hebner $^{38}$ has measured trapping of radiation in discharges similar to ours and has concluded that non-radiative quenching rates are significant, so we cannot safely neglect them in our discharge. 
As a result of this optical trapping, the light emerging from the discharge at our entrance slit may vary from the light striking the wafer in a manner depending in a complex way on plasma uniformity, optical trapping and non-radiative quenching processes in the discharge. The DPS chamber has been carefully designed to produce a uniform plasma. However, we still expect the discharge to be somewhat more intense near the wafer than at the edge of the discharge near the spectrometer slit. Thus, the intensity of the light striking the wafer is probably somewhat higher than the values we report in this paper. Since most VUV transitions terminate on ground states, this optical trapping problem is likely to occur in a wide variety of plasma processing discharges. As a result, highly accurate VUV fluxes to the wafer will probably only be obtained for most high-density plasma processing discharges by arranging to have the spectrometer look directly through a hole in the wafer.

Mechanisms of Trapped Charge Buildup in Oxide Layers:

In considering trapped charge buildup to $\mathrm{SiO}_{2}$ layers in microelectronic devices, we will consider two different classes of $\mathrm{SiO}_{2}$ layers: the relatively thin gate oxide layers and the thicker deposited oxides which serve as interlevel dielectrics or which provide isolation between adjacent transistors. The gate oxide layers may be less than $\sim 10$ $\mathrm{nm}$ thick, whereas a deposited oxide may be as much at 1 micron thick. The edges of the gate oxides will be exposed during the over-etch process during transistor gate etching ( polysilicon etching often uses chlorine-containing discharges similar to the ones studied here ) and the thick deposited oxides will be exposed during the overetch process during etching of the metal interconnects. In some cases, it is possible 
to anneal out the damage caused by VUV photons by raising the microelectronic circuits to high temperatures. This is problematic however, for devices that already have aluminum interconnects, or that have thin doping layers.

In attempting to understand how these VUV photons could cause damage in the $\mathrm{SiO}_{2}$ dielectrics on the wafer, it is important to understand how deeply these photons will penetrate into the $\mathrm{SiO}_{2}$ before being absorbed. Figure 8 shows plots of the absorption coefficients and 1/e penetration depths of VUV photons in vitreous $\mathrm{SiO}_{2}$ (fused silica) as a function of wavelength calculated from work by Philipp ${ }^{39}$.

Most work considering VUV photon damage in $\mathrm{SiO}_{2}$ has examined photons with energies of $10 \mathrm{eV}$ or higher. Above $10 \mathrm{eV}$, the absorption coefficient of $\mathrm{SiO}_{2}$ is on the order of $10^{6} \mathrm{~cm}^{-1}$ indicating that the photons will be absorbed in the first $10 \mathrm{~nm}$. In the discharges studied in our experiments, however, most of the VUV light was between 8.9 and $9.3 \mathrm{eV}$. In this energy band, the absorption coefficient of $\mathrm{SiO}_{2}$ is on the order of $10^{4} \mathrm{~cm}^{-1}$ indicating that the $1 / \mathrm{e}$ penetration depth of the light into the $\mathrm{SiO}_{2}$ will be roughly 1 micron. But the thin gate oxides in MOS devices are typically only $\sim 10 \mathrm{~nm}$ thick. This leads to an important conclusion. Most of the vacuum ultraviolet light produced in our discharges will be transmitted through any exposed thin gate oxide layers and will be absorbed in the silicon layer underneath the gate oxide. A careful matching of the emissions observed in these experiments to the absorption coefficient versus wavelength suggests that only about $7 \times 10^{12}$ photons $/ \mathrm{cm}^{2} \mathrm{sec}$ will be absorbed in a 10-nm thick oxide layer with an aluminum 
metal, bare silicon, or photoresist-covered wafer in the tool. It is interesting to note that about $2 / 3$ of the light absorbed in the thin oxide layers comes from the four relatively weak emission lines between 116 and $121 \mathrm{~nm}$. Most of the VUV light we saw in these experiments will be absorbed in the much thicker deposited oxides on a wafer.

Vacuum ultraviolet photons can contribute to three categories of trapped charges in oxides $^{40}$ 1) Interface trapped charge, which is trapped in dangling bonds at the $\mathrm{Si} / \mathrm{SiO}_{2}$ interface and is in electrical contact with the $\mathrm{Si}, 2$ ) fixed oxide charge, which is trapped in the region within $3 \mathrm{~nm}$ of the $\mathrm{Si} / \mathrm{SiO}_{2}$ interface, but which is not in electrical communication with the silicon, 3) oxide trapped charge, which is in the bulk of the $\mathrm{SiO}_{2}$ (Fixed oxide or oxide trapped charges involving a broken bond are often called $E^{\prime}$ centers.)

If we consider source and loss terms for VUV photon-induced trapped charges in the oxides, we see only one source term: i.e. electron - hole (e-h) pair production in the oxide. The holes produced in this way can become trapped at or near the $\mathrm{Si} / \mathrm{SiO}_{2}$ interface or in the bulk $\mathrm{SiO}_{2}$. We can, however, identify a number of loss terms. First, electron hole pairs can immediately recombine ${ }^{15}$. Second, a hole can undergo delayed recombination by recombining an electron from a subsequent $e-h$ pair. Third, a hole may be lost through "geometric" or boundary losses when the hole drifts away from the $\mathrm{Si} / \mathrm{SiO}_{2}$ interface to a boundary such as the $\mathrm{Si} /$ metal or $\mathrm{Si} /$ vacuum interface. Fourth, UV photons with energies greater than $4.2 \mathrm{eV}$ that are transmitted through the 
oxide and absorbed in the Si can eject photoelectrons back into the oxide, and holes can recombine with these photoelectrons..$^{41,42,43}$

Examples of Trapped Charge Buildup in Oxides:

We will now give numerical examples of trapped charge buildup in oxides at two different sites. The two sites are the exposed edges of thin gate oxides and the thick deposited oxides between transistors. For each site, we will examine two different types of trapped charge: 1) fixed oxide charges near the $\mathrm{Si} / \mathrm{SiO}_{2}$ interface and 2) $\mathrm{E}$ ' centers, which correspond roughly to trapped oxide charges in the bulk of the oxide. These examples are somewhat speculative as they rely on incomplete information. In examining trapped charge buildup in the examples that follow, we will be looking only at the VUV source term and the immediate recombination term, since those are the only terms for which efficiency numbers are available. The other, unquantified loss terms may reduce the trapped charge buildup in each of the cases we list below.

Thin Gate Oxides:

To examine trapped charge buildup around the edges of thin gate oxides, we note that Yunogami et. al. ${ }^{15}$ have examined the efficiency with which absorbed VUV photons generate trapped holes near the interface. Yunogami finds that the probability of producing trapped holes at the interface depends on how much thermal energy the electron-hole pair has when it is created and how far the hole has to diffuse before reaching the $\mathrm{Si} / \mathrm{SiO}_{2}$ interface. The more energy the photon has above $\sim 8.8$ $\mathrm{eV}$, the larger thermal energy the electron-hole pair will have and the less likely they 
will be to immediately recombine. The farther the hole has to diffuse before reaching the $\mathrm{Si} / \mathrm{SiO}_{2}$ interface, the more likely it is to recombine with an electron. As a result, Yunogami et. al. find that the efficiency of trapped hole production is quite low, about 0.002 trapped holes / VUV photon absorbed in a 100-nm-thick oxide layer, at the wavelengths observed in our experiments. The efficiency of trapped hole production rises sharply with increasing photon energy, however, becoming approximately 0.02 for $20 \mathrm{eV}$ photons. For our discharges with a reactive wafer on the wafer chuck, about $2 \times 10^{13}$ photons $/ \mathrm{cm}^{2} \mathrm{sec}$ will be absorbed in a $100-\mathrm{nm}$ thick $\mathrm{SiO}_{2}$ layer. Using Yunogami's efficiency value of 0.002 trapped holes/photon, this implies that about $4 \times 10^{10}$ trapped holes $/ \mathrm{cm}^{2}$ sec would be generated. In a 10 second over-etch run, about $4 \times 10^{11}$ trapped holes $/ \mathrm{cm}^{2}$ would be produced.

VUV photons have also been shown to cause charge buildup in $\mathrm{SiO}_{2}$ by formation of $E^{\prime}$ centers ${ }^{13,14} . E^{\prime}$ centers are relatively immobile and hence, after they are created in an area that has a line-of-sight to the VUV photons, are not likely to diffuse under the edges of the gate material to the high-field region of the thin gate oxide. Yokogawa et. al. ${ }^{14}$ have measured the production of $\mathrm{E}^{\prime}$ centers in $\mathrm{SiO}_{2}$ by $16-\mathrm{eV}$ photons. Their results suggest a production efficiency on the order of $2.5 \times 10^{-4} \mathrm{E}^{\prime}$ centers /16-eV photon. Since the creation of $E^{\prime}$ centers is barely energetically possible with the 8.9$10.6 \mathrm{eV}$ photons observed in our discharges, we assume that the $\mathrm{E}^{\prime}$ center production efficiency in our discharges is at least no higher than the value measured in Yokogawa's experiments with $16-\mathrm{eV}$ photons. In a 10-second over-etch, 10-nmthick gate oxides exposed to the VUV fluxes in our experiments will absorb $\sim 7 \mathrm{x}$ 
$10^{13}$ photons $/ \mathrm{cm}^{2}$. Using Yokogawa's efficiency, this suggests that no more than $\sim 1.7 \times 10^{10} \mathrm{E}^{\prime}$ centers $/ \mathrm{cm}^{2}$ would be formed in the thin gate oxides.

\section{Thick Deposited Oxides:}

As a second example, we will examine the effect of trapped charge buildup in the thick oxides deposited over the Si substrate in the areas between adjacent transistors. When enough positive charge builds up in the oxide, the doped Si substrate can invert and become conductive. This can lead to leakage of current between source and drain regions or adjacent transistors. This "cross-talk" can lead to device failure. Work by $\mathrm{Sze}^{44}$ indicates that trapped oxide charge densities of $8.7 \times 10^{10} / \mathrm{cm}^{2}$ and $3.2 \times 10^{11} / \mathrm{cm}^{2}$ will invert P-type silicon substrates doped at $10^{15} / \mathrm{cm}^{3}$ and $10^{16} / \mathrm{cm}^{3}$ respectively.

We will first look at $E^{\prime}$ centers in the bulk oxide, using Yokogawa' ${ }^{14}$ efficiency numbers for $16 \mathrm{eV}$ photons. Approximately $81 \%$ of the $\sim 7 \times 10^{13} / \mathrm{cm}^{2} \mathrm{sec}$ VUV photons observed in these experiments will be absorbed in passing through a $1000 \mathrm{~nm}$ thick deposited oxide. Using Yokogawa's efficiency of $E^{\prime}$ center generation for 16 $\mathrm{eV}$ photons of $2.5 \times 10^{-4}$ suggests that our absorbed VUV flux should generate $1.4 \mathrm{x}$ $10^{11} \mathrm{E}^{\prime}$ centers $/ \mathrm{cm}^{2}$ during a 10 second overetch run. This is almost a factor of two more $E^{\prime}$ centers than are needed to invert a P-type Si layer doped at $10^{15} / \mathrm{cm}^{3}$. Second, look at trapped hole generation near the interface in a $1000 \mathrm{~nm}$-thick film using Yunogami's ${ }^{15}$ efficiency numbers. We consider only holes generated within $100 \mathrm{~nm}$ of the interface, since Yunogami's experiments were for trapping in 100-nm- 
thick oxide films over Si. Approximately $2 \times 10^{12}$ photons $/ \mathrm{cm}^{2} \mathrm{sec}$ will be absorbed in the bottom $100 \mathrm{~nm}$ layer of oxide. Using Yunogami's 0.002 efficiency number indicates that $\sim 4 \times 10^{10}$ trapped holes would be generated near the interface in a 10 second overetch. This is within a factor of two of the value needed to invert a P-type substrate doped at $10^{15} / \mathrm{cm}^{3}$.

\section{Summary:}

All of the VUV emission features seen in these experiments at photon energies above the 8.8-eV $\mathrm{SiO}_{2}$ band gap energy were between 8.8 and $12.7 \mathrm{eV}$. Most of the emission features we observed were resonance lines of neutral chlorine atoms and were between 8.8 and $9.3 \mathrm{eV}$ ( 140 to $132 \mathrm{~nm}$ ). We saw no emission features between 12.7 and $18 \mathrm{eV}$ and no chlorine ion lines. With a reactive wafer in the tool, the VUV photon flux to the center of the wafer was on the order of $7 \times 10^{13}$ photons $/ \mathrm{cm}^{2}$ sec. Flux measurements were complicated by the fact that the chlorine resonance lines we observed were strongly radiation trapped in the discharge. Because of this radiation trapping, high accuracy measurements of VUV fluxes to the wafer in these high density discharges will probably require that the spectrometer look directly through a hole in the wafer itself. In contrast to the strong selfabsorption of the VUV light in the plasma, the absorption depth of the photons observed in these experiments in $\mathrm{SiO}_{2}$ is relatively large - on the order of one micron. Hence, these photons are absorbed in the bulk of the $\mathrm{SiO}_{2}$, not just in a thin surface layer. 
Roughly $7 \times 10^{12}$ photons $/ \mathrm{cm}^{2}$ sec from our discharges will be absorbed in a 10-nmthick gate oxide layer and about $2 \times 10^{13}$ photons $/ \mathrm{cm}^{2} \mathrm{sec}$. will be absorbed in a 100nm-thick layer. These VUV photons will create electron hole pairs when they are absorbed in $\mathrm{SiO}_{2}$. There are a number of potential loss terms that could prevent these holes from becoming trapped charge in the oxide. However, reaction rates for most of these loss terms are not known. Using only the source and loss terms for which we do have rates, we estimate that exposing a 100-ns thick oxide layer to the VUV photon fluxes from our discharges during a 10 -second over-etch procedure would result in about the production of about $4 \times 10^{11}$ trapped holes close to the $\mathrm{Si} / \mathrm{SiO}_{2}$ interface. We also estimate that the VUV photons in our discharges could produce $\sim 10^{10} \mathrm{E}^{\prime}$ centers $/ \mathrm{cm}^{2}$ in a thin gate oxide during a $10 \mathrm{sec}$. overetch. Finally, we estimate that enough trapped holes or E' centers could be produced in thick deposited oxides during a $10 \mathrm{sec}$ overetch run to invert lightly-doped Si substrates.

The absorption cross sections for $\mathrm{SiO}_{2}$ are strong functions of wavelength in the VUV. Therefore, small shifts in the wavelengths of the emitting species would change the rate of VUV-photon-induced trapped charge buildup by several orders of magnitude. In order to determine whether VUV photon fluxes do cause significant device damage, it will be necessary to first to examine the VUV spectra of each class of gas mixtures used in etching of microelectronic circuits and then to experimentally measure device damage as a function of VUV flux, for the photon energies of interest. 


\section{Acknowledgements:}

The authors would like to acknowledge a number of helpful discussions with Drs.

Paul Miller, Greg Hebner, Merle Riley, and Peter Winokur of Sandia National

Laboratories and with Dr. Peter Loewenhardt of Applied Materials Corp. This

research was supported by the United States Department of Energy under contract \#

DE-AC04-94AL85000 and by SEMATECH. Sandia is a multiprogram laboratory

operated by the Sandia Corporation, a Lockheed-Martin Company, for the United

States government. 
Figure Captions:

Figure 1: Schematic of the vacuum UV spectrometer coupled to the Applied DPS tool. Note that only the spectrometer entrance slit excludes the DPS plasma from the spectrometer. There is no window between the two devices.

Figure 2: Schematic of the apparatus used to calibrate the absolute sensitivity of the Seya-Namioka spectrometer plus its detectors. The VUV light source plus 1-meter spectrometer provided a monochromatic input beam to the SEYA. The signal from the NIST-calibrated diode was compared to the signal from the SEYA detector to determine the overall sensitivity of the SEYA system.

Figure 3: Sensitivity curve of the SEYA spectrometer with the Channeltron ${ }^{\mathrm{TM}}$ detector. The sensitivity depends strongly on wavelength.

Figure 4: Absolute photon flux at the center of the wafer as a function of wavelength for a $10 \mathrm{mTorr} \mathrm{Cl}_{2} / \mathrm{BCl}_{3}$ discharge with $1100 \mathrm{~W}$ source and $200 \mathrm{~W}$ bias power. This spectrum was taken with an aluminum oxide ceramic wafer in the tool. This spectrum was taken with the SEYA spectrometer and the 
Channeltron ${ }^{\mathrm{TM}}$ detector. All the lines at wavelengths longer than $115 \mathrm{~nm}$ are due to neutral atomic chlorine.

Figure 5: Detail of unidentified emission lines seen in Fig. 4 between 95 and $115 \mathrm{~nm}$.

Figure 6: Absolute photon fluxes at the center of the wafer between 110 and $250 \mathrm{~nm}$ for a $10 \mathrm{mTorr} \mathrm{Cl}_{2} / \mathrm{BCl}_{3}$ discharge with $1100 \mathrm{~W}$ source and $200 \mathrm{~W}$ bias power. This data was taken with the SEYA plus photomultiplier tube system. An aluminum oxide wafer was in the DPS tool.

Figure 7: Plot of the absolute VUV flux to the wafer (above $8.8 \mathrm{eV}$ ) for $10 \mathrm{mTorr}$ discharges in $\mathrm{Cl}_{2}$ and $\mathrm{BCl}_{3}$ as a function of total rf power applied to the discharge. Source/Bias power levels are listed next to each point. A point for a pure argon discharge is also shown at $1100 \mathrm{~W} / 0 \mathrm{~W}$.

Figure 8: Plots of the VUV absorption Coefficients and 1/e photon penetration distances in fused quartz. 
Table I: Absolute intensities of neutral chlorine lines at center of ceramic wafer for $10 \mathrm{mTorr} \mathrm{Cl}_{2} / \mathrm{BCl}_{3}$ mixture powered by $1100 \mathrm{~W}$ source and $200 \mathrm{~W}$ bias power

\begin{tabular}{|l|l|}
\hline Wavelength of line $(\mathrm{nm})$ & $\begin{array}{l}\text { Photons } / \mathrm{cm}^{2} \text { sec to center of wafer } \\
\left(\div 10^{13}\right)\end{array}$ \\
\hline & \\
\hline 116.7 & 0.2 \\
\hline 117.7 & 2.0 \\
\hline 118.7 & 1.95 \\
\hline 120.1 & 1.27 \\
\hline 133.6 & 1.8 \\
\hline 134.7 & 3.0 \\
\hline 135.1 & 3.5 \\
\hline 136.4 & 8.0 \\
\hline 137.2 & 0.8 \\
\hline 137.7 & 4.0 \\
\hline 138.7 & 14.0 \\
\hline 139.4 & 8.0 \\
\hline Total intensity & $48.5 \times 10^{13} \mathrm{photons} / \mathrm{cm}^{2} \mathrm{sec}$ \\
\hline
\end{tabular}


Table II: Fluxes of Photons above $8 \mathrm{eV}$ as a function of wafer Type; $1100 \mathrm{~W}$ source, $200 \mathrm{~W}$ bias, $10 \mathrm{mTorr}, 100 \mathrm{sccm} \mathrm{Cl}, 40 \mathrm{sccm} \mathrm{BCl}$

wafer type

photons $/ \mathrm{cm}^{2} \mathrm{sec}$

$\mathrm{mW} / \mathrm{cm}^{2}$

ceramic

$4.8 \times 10^{14}$

0.7

Al Metal

$0.7 \times 10^{14}$

0.1

Silicon

$0.7 \times 10^{14}$

0.1

Photoresist

$0.8 \times 10^{14}$

0.11

Table III: photon fluxes above $8 \mathrm{eV}$ as a function of pressure: , $1100 \mathrm{~W}$ source, $200 \mathrm{~W}$ bias, $10 \mathrm{mTorr}, 100 \mathrm{sccm} \mathrm{Cl}_{2}, 40 \mathrm{sccm} \mathrm{BCl}_{3}$

pressure

$5 \mathrm{mT}$ orr

$10 \mathrm{mTorr}$

20 mTorr photons $/ \mathrm{cm}^{2} \mathrm{sec}$

$2 \times 10^{14}$

$3.4 \times 10^{14}$

$3.7 \times 10^{14}$
0.49

$\mathrm{mW} / \mathrm{cm}^{2}$

0.3

0.54 
Table IV: Effect of adding Argon to a $\mathrm{Cl}_{2} / \mathrm{BCl}_{3}$ discharge with a ceramic wafer: $7 \mathrm{mTorr}$ total pressure, $60 \mathrm{sccm} \mathrm{Cl}_{2}, 30 \mathrm{sccm} \mathrm{BCl}{ }_{3}, 900 \mathrm{~W}$ source, $185 \mathrm{~W}$ bias

$\begin{array}{lll}\text { Argon flow } & \text { photons } / \mathrm{cm}^{2} \mathrm{sec} & \mathrm{mW} / \mathrm{cm}^{2} \\ 0.0 & 3.3 \times 10^{14} & 0.48 \\ & & \\ 50 \mathrm{sccm} & 3.8 \times 10^{14} & 0.55\end{array}$

Table V: Data Taken with photomultiplier tube: $10 \mathrm{mTorr}, 100 \mathrm{sccm} \mathrm{Cl}{ }_{2} 40 \mathrm{sccm} \mathrm{BCl}$ $10 \mathrm{mTorr}$ total pressure, $1100 \mathrm{~W}$ source, $200 \mathrm{~W}$ bias

wafer type

ceramic

Al metal photons $/ \mathrm{cm}^{2} \mathrm{sec}$ to wafer center

$2.5 \times 10^{14}$

$0.3 \times 10^{14}$
$\mathrm{mW} / \mathrm{cm}^{2}$ to wafer center

$0.36 \mathrm{~mW} / \mathrm{cm}^{2}$

$0.04 \mathrm{~mW} / \mathrm{cm}^{2}$ 
1 G. S. Oehrlein, Materials Science and Engineering B4, 441, (1989)

2 K. H. Ryden, H. Norstrom, C. Nender and S. Berg, J. Electrochem. Soc.: Solid State Science \& Technology, 134, 3113, (1987)

3 A. W. Flounders, S. A. Bell, D. W. Hess, J. Electrochem. Soc, 140, 1414, (1993)

4 P. A. Miller, D. M. Fleetwood and W. K. Schubert, J. Appl. Phys, 69, 488, (1991)

T. Tatsumi, S. Fukuda, and S. Kadomura, Jpn. J. Appl. Phys, 32, 6114, (1993)

6

C. Cardinaud, G. Turban, B Grolleau, J. P. Grandchamp, C. Lejeune, P.

Scheiblin,m and E. Collard, Applied Surface Science, 36, 332, (1989)

S. Yokoyama, Z. J. Radzimski, K. Ishibashi, S. Miyazaki, M. Hirose, Jpn. J. Appl. Phys, 33, Part 1, 2179, (1994)

K. Yokogawa, Y. Yajima, T. Mizutani, Jpn. J. Appl. Phys, 30, 3199, ( 1991)

9 T. Yunogami and T. Mizutani, J. Appl. Phys, 73, 8184, (1993)

10 T. Ono, N. Itabashi, I. Ochiai, S. Yamamoto, K. Mochiji, Jpn. J. Appl. Phys, 36, Part 1, 6718,(1997)

11 T. Mizutani, S. Nishimatsu, T. Yunogami, Materials research Society Symposium Proceedings, 128, 605, (1989)

12 T. Kang, S. Ueng, B. Dai, L. Chen, H. Cheng, Jpn. J. Appl. Phys 34, Part 1, 2272, (1995)

13 T. Yunogami, T. Mizutani, K. Tsujimoto, and K. Suzuki, Jpn. J. Appl. Phys, 29, Part 1, 2269,( 1990) 
K. Yokogawa, Y. Yajima, T. Mizutani, S. Nishimatsu, K. Suzuki, Jpn. J. Appl.

Phys, 29, Part 1, 2265, (1990)

T. Yunogami, T. Mizutani, K. Suzuki, and S. Nishimatsu, Jpn. J. Appl. Phys, 28, 2172, (1989)

T. Tatsumi, S. Fukuda, S. Kadomura, Jph. J. Appl. Phys, 33, Part 1, 2175, (1994)

C. M. Dozier, D. B. Brown, IEEE Trans on Nuclear Sci. NS-28, 4137, (1981)

C. M. Dozier, D. B. Brown, R. K. Freitag, and J. L. Throckmorton, IEEE Trans on Nuclear Sci. NS-33, 1324, (1986)

S. Fang and J.P. McVittie, J. Appl. Phys 72(10), 4865, (1992)

S. Fang and J. P. McVittie, Appl. Phys. Lett, 62, 1507, (1993)

S. Murakawa, J. P. McVittie, Jpn. J. Appl. Phys, 33, Part 1, 2184, ( 1994)

S. Ma, M. Jain, J. D. Chinn, J. Vac. Sci. Technol. A, 16, 1440, (1998)

D. L. Griscom and W. B. Fowler, Proceedings of the International Topical Conference on MOS Insulators, Raleigh, NC, (1980) p. 97, Pergamon Press, NY, NY. ISBN 0-08-025969-3

A. C. Fozza, A. Kruse, A. Hollander, A. Ricard, M. R. Wertheimer, J. Vac. Sci.

Technol. A, 16, 72 (1998)

S. Miyake, W. Chen, T. Ariyasu, Jpn, J. Appl. Phys, 29, 2491, (1990).

K. Krisnan, B. Hallet, J. Schnell, T. R. Webb, J. Shiau, P. K. Loewenhardt, and D. X. Ma, Tech. Dig. Intl. Electron Devices Meeting,315, ( 1995)

R. E. Vest, National Institute of Standards and Technology, Gaithersburg, MD, rvest@nist.gov 
J. R. Woodworth, PHD Thesis, Dept. of Physics, The Johns Hopkins University, 1974. Available from University Microfilms, Ann Arbor Michigan.

J. R. Woodworth, M. E. Riley, R. A. Miller, C. A. Nichols, and T. W. Hamilton, J. Vac. Sci. Technol. A 15, 3015, 1997

T. Holstein, Phys. Rev. 72, (12), 1212, (1947)

J. Huennekens and T. Colbert, J. Quant. Spectros. Radiat. Transfer 41, (6) 439, (1989)

T. Holstein, Phys. Rev. 83 (6), 1159,(1951)

M. E. Riley, W. J. Alford, Radiation Trapping in Plasmas, Sandia Report SAND95-1201. UC-401, June 1995

R. M. Forrister and H. M. Anderson, Program of the $48^{\text {th }}$ Gaseous Electronics

Conf. Paper EA-8 Bulletin of the American Physical Society 40, (9) Oct. 1995

W. L. Wiese, M. W. Smith, B. M. Miles, Atomic Transition Probabilities, 2, National Bureau of Standards, NSRDS-NBS 22, October, 1969

A. C. G. Mitchell and M. W. Zemansky, Resonance Radiation and Excited Atoms, Cambridge Univ, Press, Cambridege, 1934.

G. A. Hebner, P. A. Miller, Submitted to JVSTA, 1998

H. R. Philip, Absorption coefficients of silicon dioxide, Handbook of Optical

Constants of Solids, Ed. E. D. Palik, Academic Press, New York, 749 ( 1985)

B. E. Deal, IEEE Trans on Electron Devices ED-27 (3), 606, (1980)

A. M. Goodman, Phys Rev 144, (2) 588 ( 1966)

42

R. Williams, Phys. Rev. 140, (2A), A569, (1965)

E. Kooi, Philips Res. Repts. 20, 595, (1965)

S. M. Sze, Physics of Semiconductor Devices, Wiley, NYC, 1995, ISBN: 0471-05661-8 


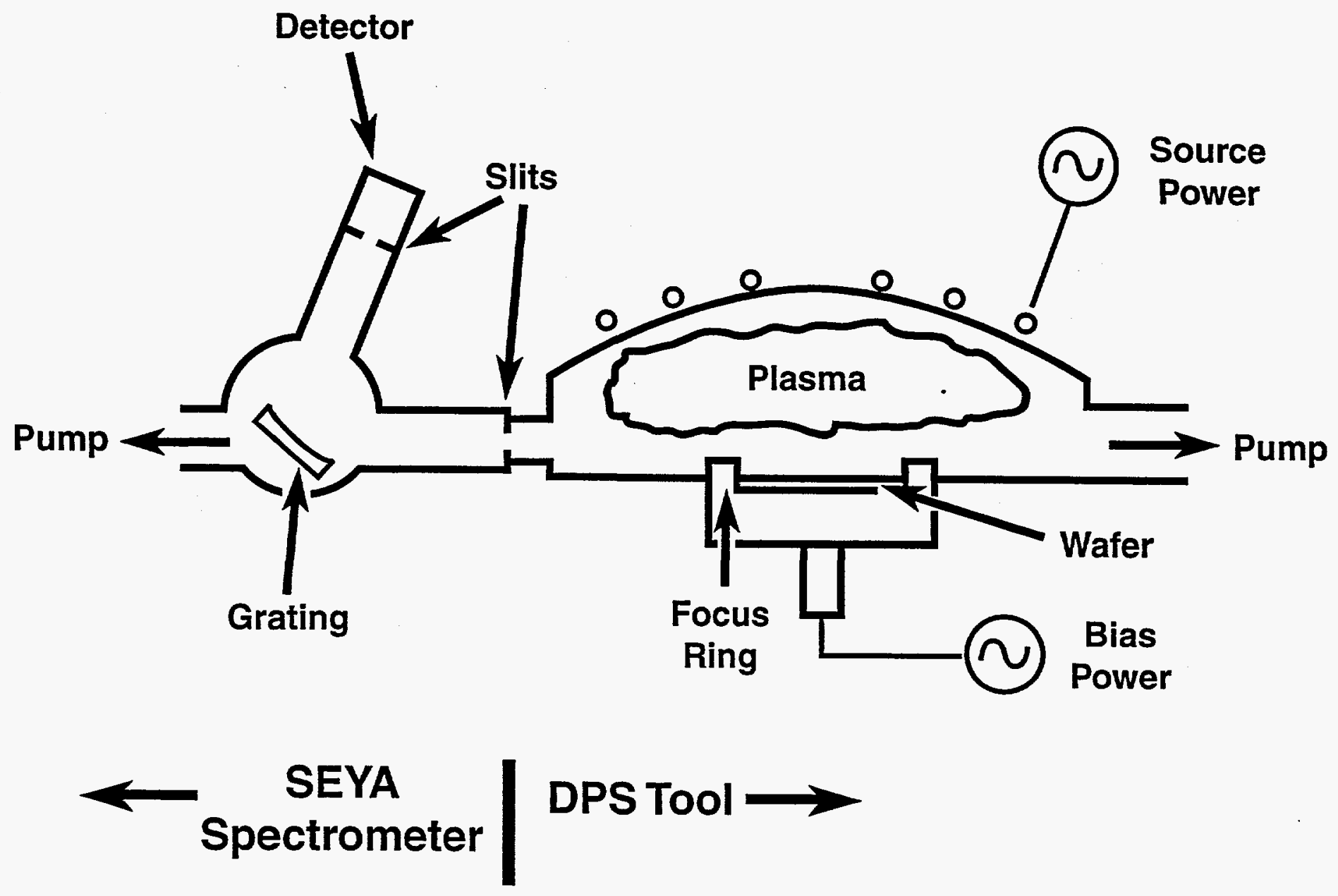

Figure 1 IR Woodwerth etal 

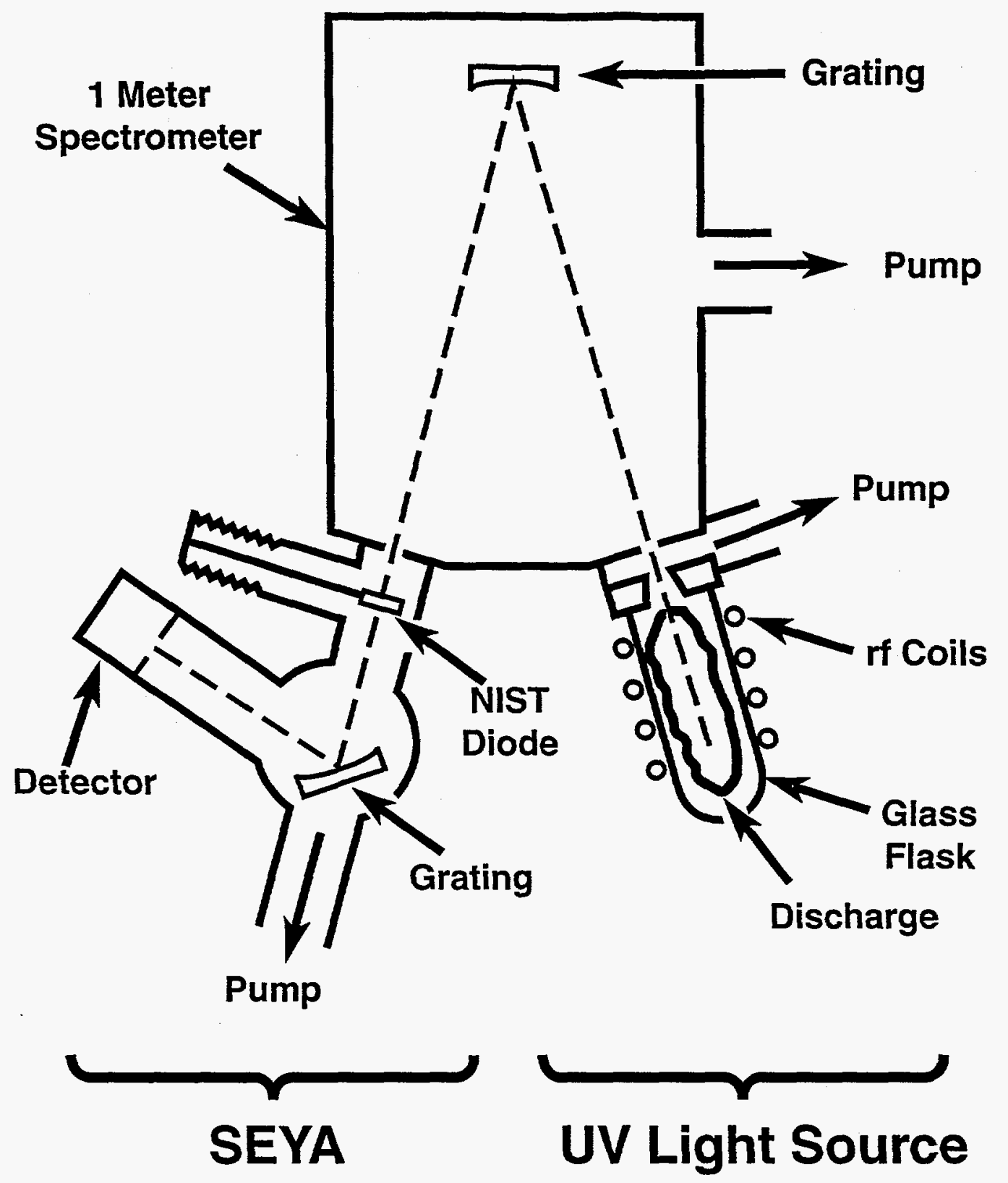
Fighe 2; JR Woodwarth ET. al JVST




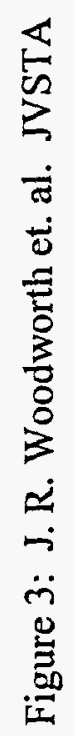

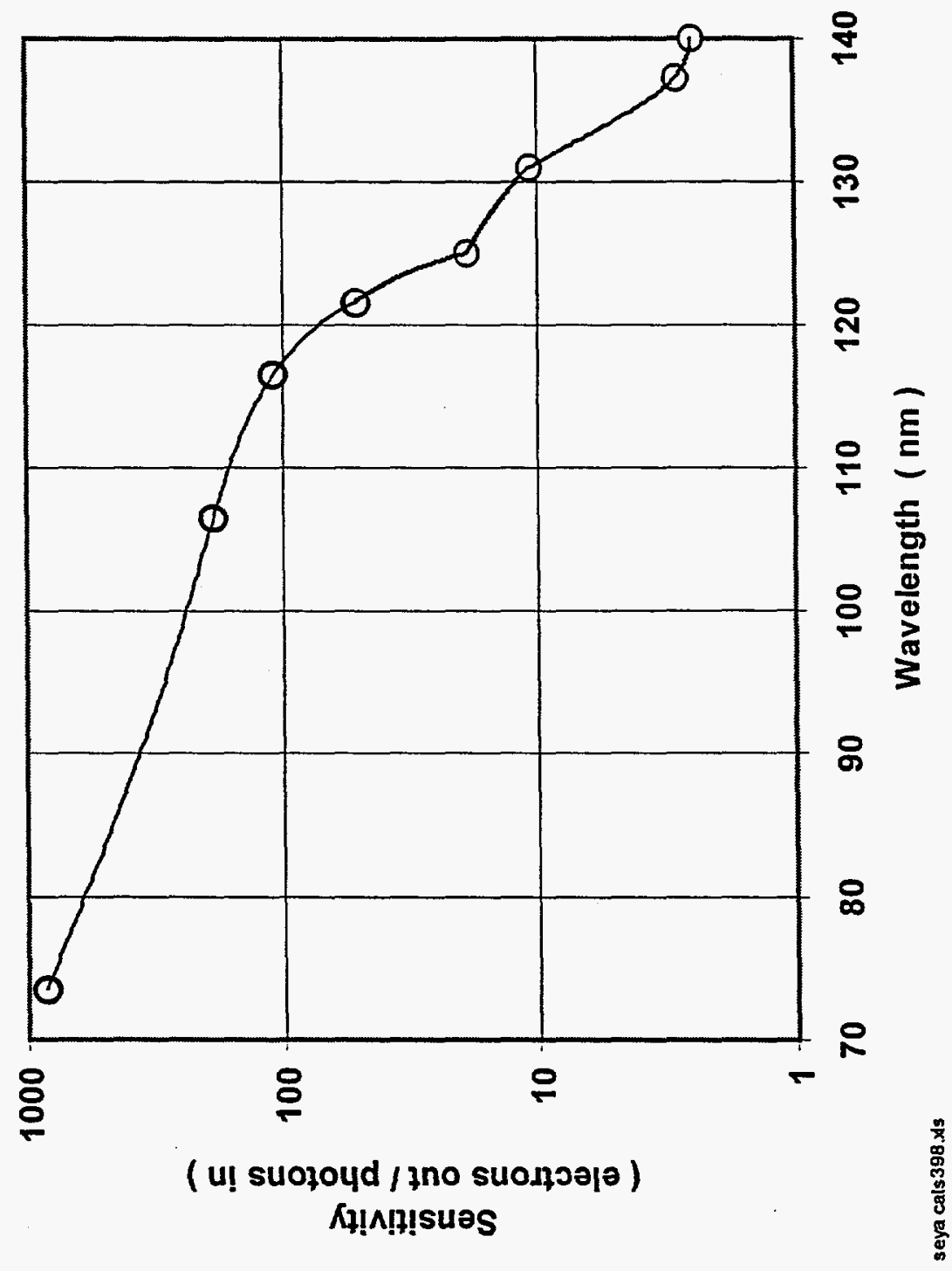




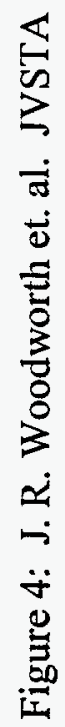

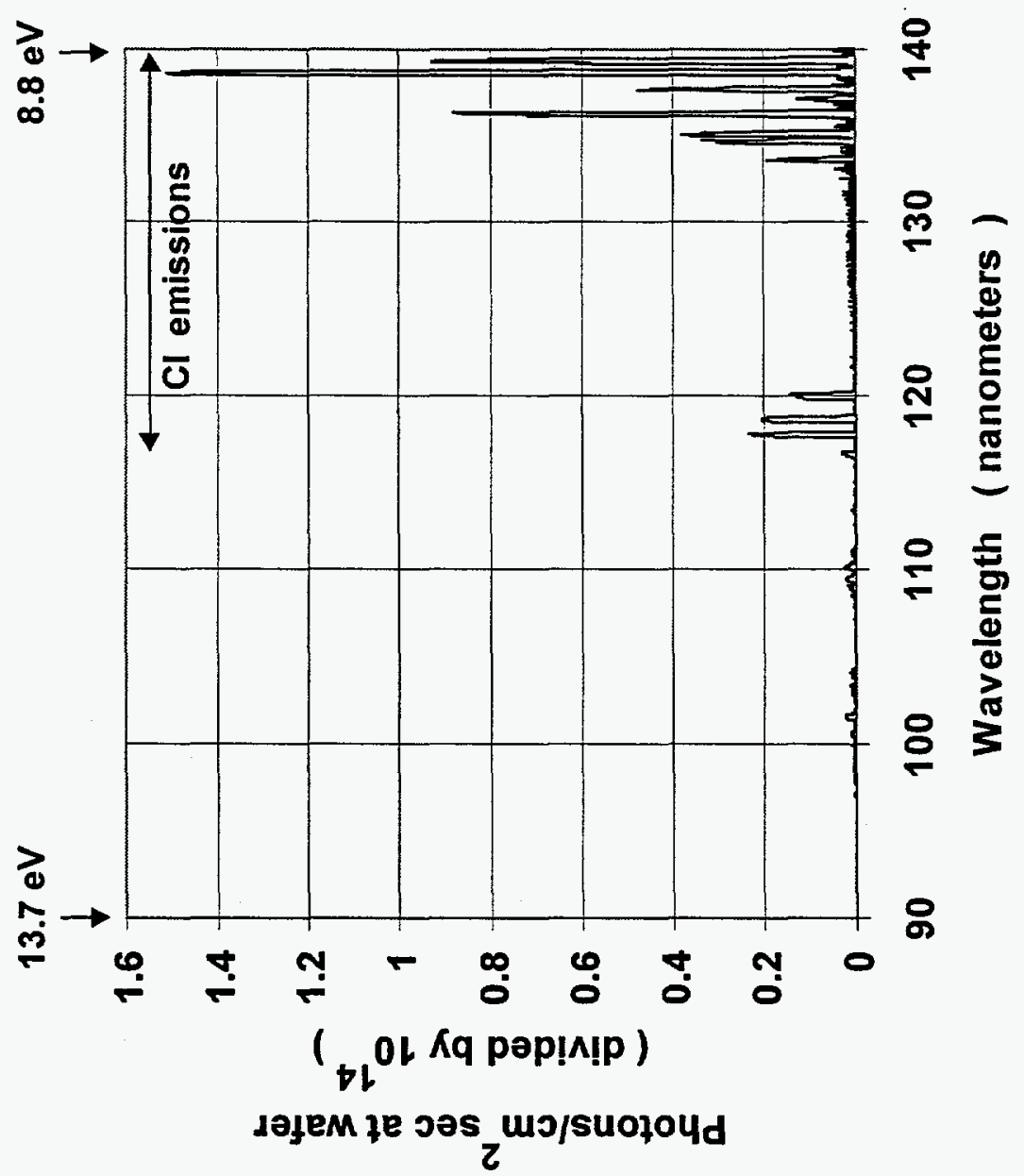




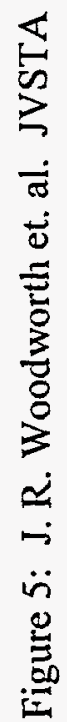

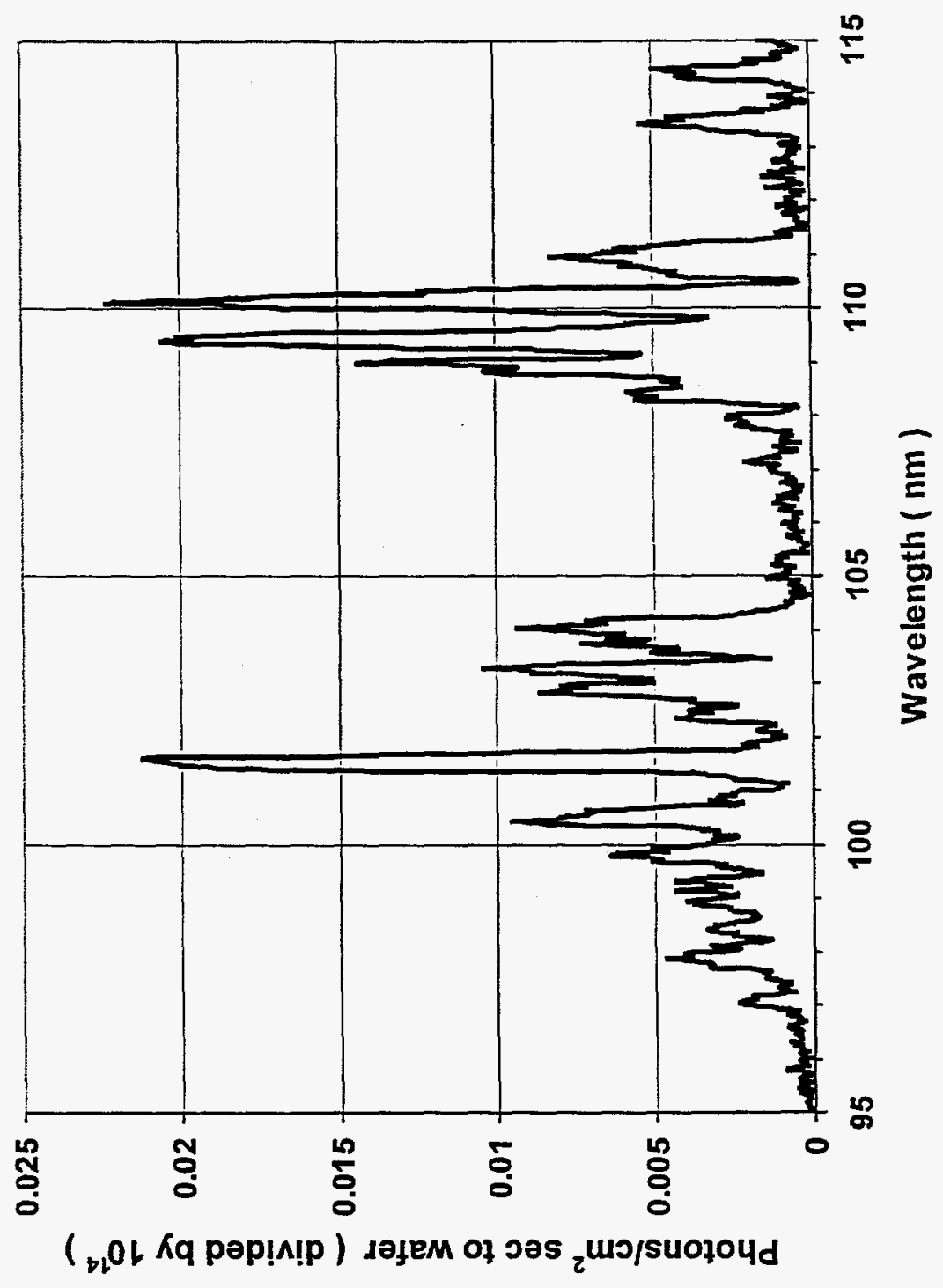




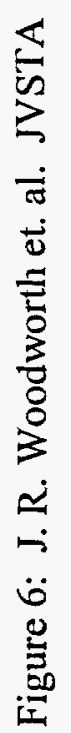

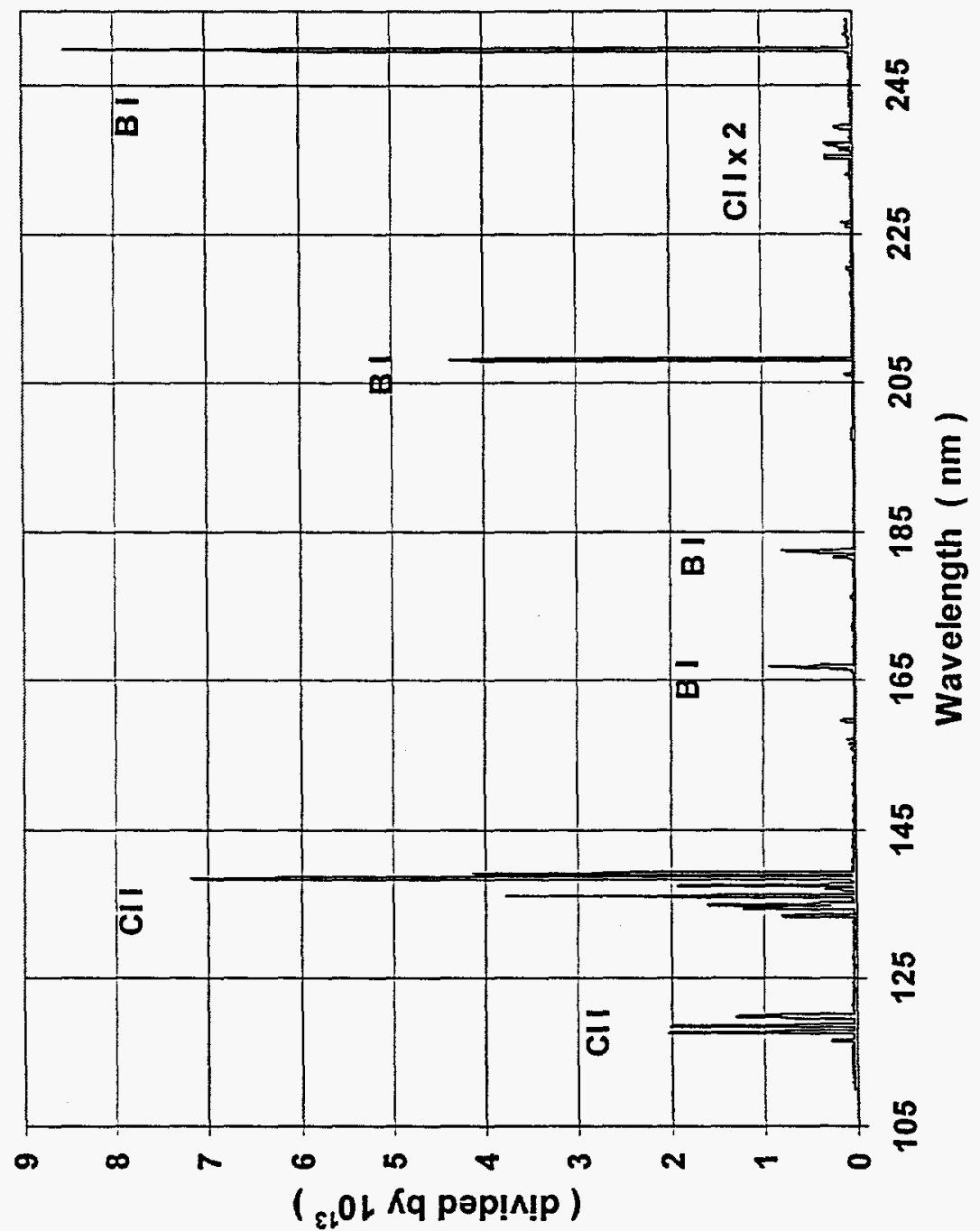

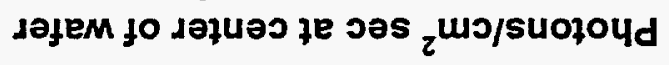




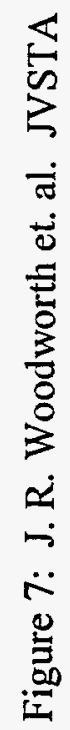

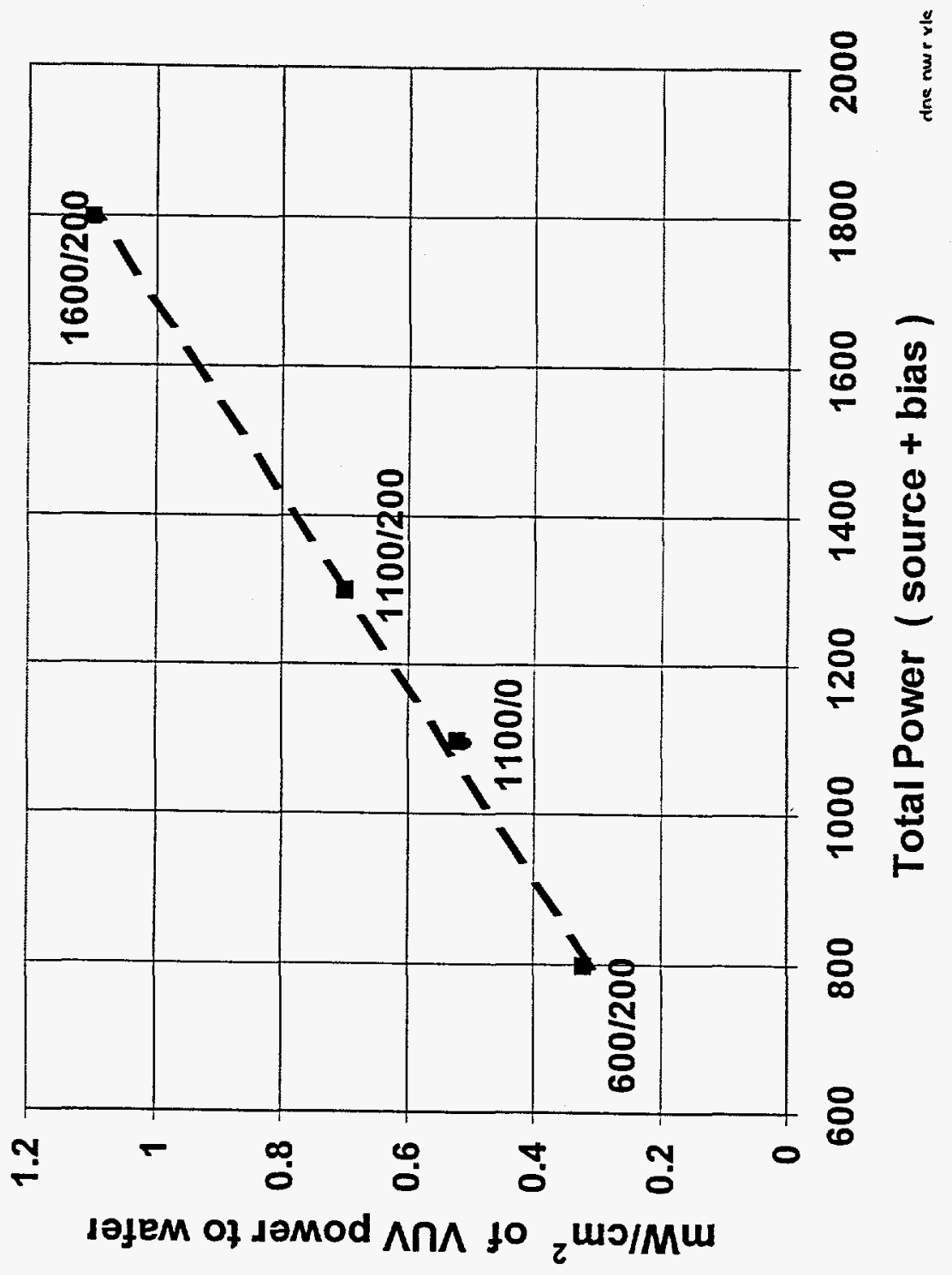




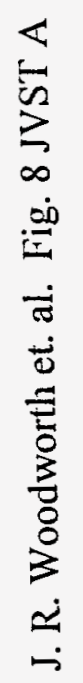

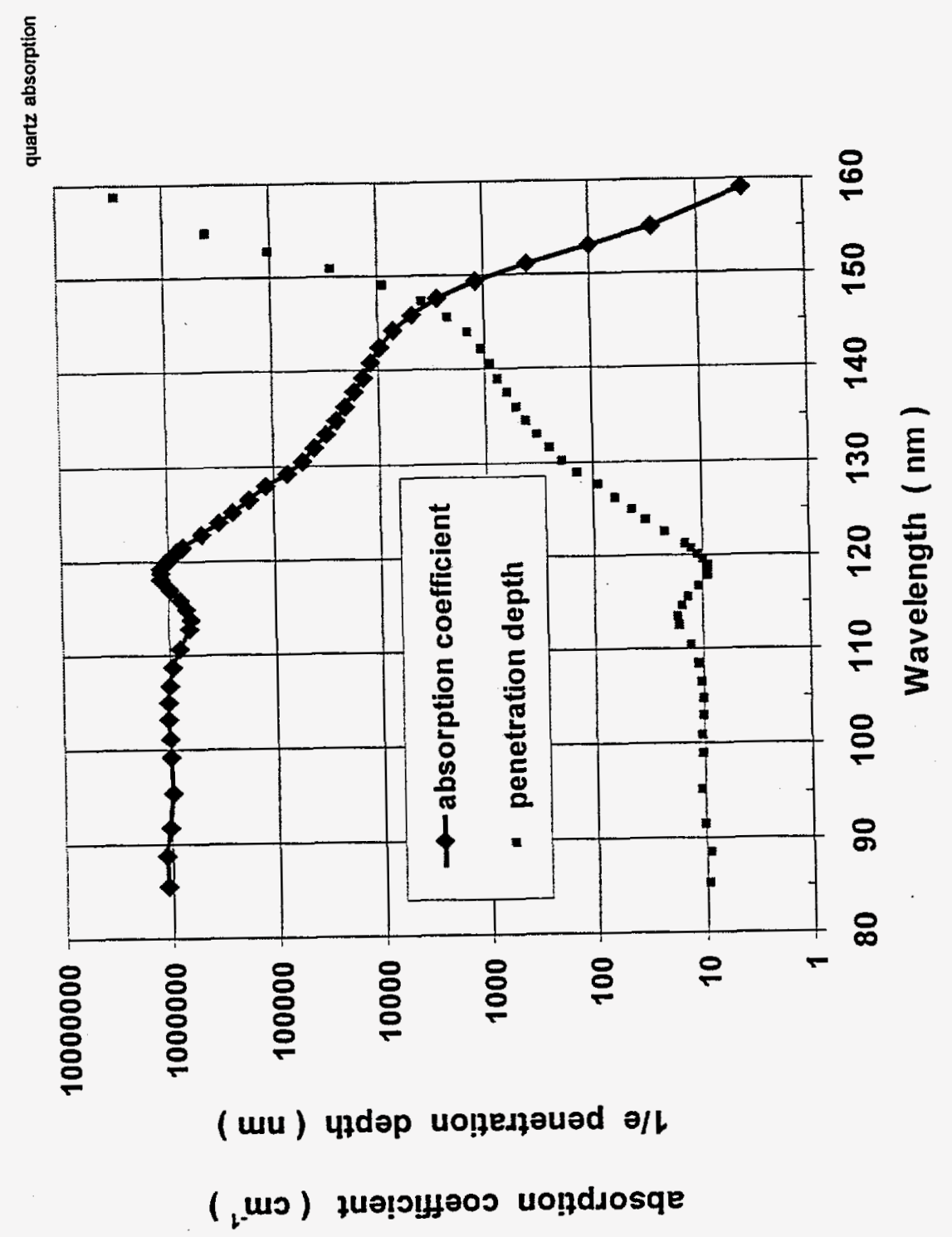

